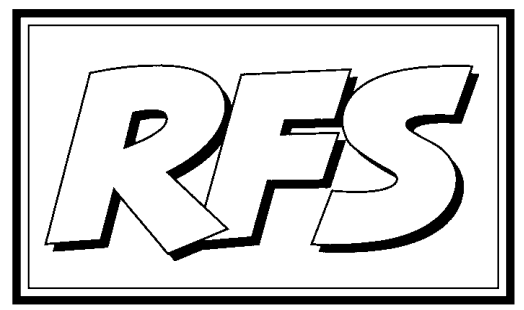

Revista de Fomento Social, 55 (2000), 13-28

\title{
Empresa y sociedad: interrogantes éticos
}

Necesidad de reflexionar éticamente sobre las actividades de la empresa

Hace dos años el Consejo de Redacción de esta Revista realizaba una primera aproximación a las relaciones existentes entre ética y empresa en un editorial que titulábamos «La ética empresarial: ¿necesidad, utilidad o pretexto?» ${ }^{1}$. Se trataba entonces de fundamentar la necesidad de una reflexión ética en el ámbito de la empresa, $y$, sobre todo, de exponer y valorar las diferentes formas de entender cómo la ética debe relacionarse con las actividades empresariales. Nos comprometíamos entonces con nuestros lectores a tratar en futuros editoriales otros aspectos de esta temática tan actual. A ello dedicamos este artículo editorial. Lo que nos mueve a ello no es sólo el compromiso contraído, sino al menos otras dos razones.

Ante todo, crece la necesidad de valorar éticamente las actividades empresariales: necesidad tanto más relevante cuanto más rápida es la pérdida

\footnotetext{
${ }^{1}$ (№ 208, octubre-diciembre 1997, pp. 459-475).
} 
de influencia de otros saberes que orientan, en alguna medida, la forma de actuar de toda persona. En un mundo cada vez más secularizado y con menos influjo social de las religiones, en un contexto de devaluación de la Política (con mayúsculas) y del compromiso político de los ciudadanos, ante una sociedad donde cada vez se solicita una mayor desregulación en el ámbito de actuación de las empresas para dejar que el mercado imponga su "pretendido" orden, es indudable que la ética está llamada a constituirse en ese saber práctico que oriente al hombre en su quehacer.

Por otra parte, la empresa se ha convertido en un concepto esencial en el mundo contemporáneo, del mismo modo, como apuntaba el profesor López Aranguren, que lo fue en la Antigüedad el concepto de religión. Al igual que el mundo antiguo no puede entenderse si se prescinde del factor religioso, las sociedades actuales tampoco pueden comprenderse si no se tiene presente qué es la empresa y cómo influye en todos los ámbitos de la vida del hombre moderno. La cultura empresarial, con sus "valores" implícitos o explícitos, se proyecta en todos los ámbitos sociales: la utilidad, el pragmatismo, la eficiencia, la competitividad, el análisis coste-beneficio se convierten en principios que transcienden del ámbito de la empresa y llegan incluso, en ocasiones, a hacerse presentes en las relaciones más íntimas, privadas 0 familiares.

Por estas dos razones, la pérdida de relevancia de los otros saberes a la hora de orientar la acción concreta de los individuos y el creciente papel de la empresa como pieza vertebradora de nuestras sociedades, la reflexión ética en el ámbito de la empresa se hace ineludible, no sólo para la actividad de la empresa misma sino incluso para la vida de toda la sociedad, que hoy está constituida por tres instituciones clave (familia, empresa y Estado).

Con estas páginas no pretendemos ofrecer un recetario de soluciones para todos los problemas que pueden producirse en el ámbito de las empresas. Nuestro objetivo es sólo suscitar en el lector algunos de los interrogantes éticos que toda actuación empresarial plantea. Esto concuerda bien con lo que pensamos deber ser toda ética aplicada. En cuanto filosofía aplicada a la realidad de la empresa, requiere que nada se dé por supuesto, como si se tratase de un a priori incuestionable. Este es sin duda uno de los principales problemas a superar por la moral cuando trata de acercarse al mundo de la economía en general y de la empresa en particular: las resistencias que encuentra en muchos científicos sociales, incluidos los que lo son en Ciencias Económicas y Empresariales, a que determinados principios o proposiciones 
de sus disciplinas se somentan a análisis críticos desde otros ámbitos del saber. Cuando desde la Filosofía moral se cuestionan ciertos principios económicos, no es infrecuente que muchos economistas y hombres de empresa suelen desmontar las críticas realizadas aludiendo al desconocimiento que de la Economía tienen los sujetos que se mueven habitualmente en otras disciplinas, o simplemente señalando que tales críticas responden a un idealismo utópico. Peso a ello la ética no puede prescindir de preguntas como éstas: ¿qué fundamenta éticamente la existencia de las empresas?, ¿qué justifica éticamente las ganancias empresariales?, ¿debe esa ganancia repercutir especialmente en los propietarios de la empresa?, ¿cómo se justifica que el poder de decisión vaya estrechamente vinculado a la condición de propietario?, etc. Pero la ética empresarial ha de ser, al mismo tiempo, un saber práctico, que desde preguntas como las descritas, guíe la acción concreta de los individuos.

\section{Partir de un concepto de empresa}

Antes de pronunciarse sobre las implicaciones éticas que cualquier hecho suscita, es imprescindible conocer de qué realidad estamos hablando. Por eso, si queremos hablar de la ética de la empresa, necesitamos, siquiera brevemente, ponernos de acuerdo sobre qué entendemos por empresa.

Aunque no conviene identificar precipitadamente empresa y empresa capitalista, es preciso reconocer que la empresa, en el sentido moderno de la palabra, nació con el capitalismo. Y el término mismo escogido refleja la mentalidad dominante en aquellos momentos. En efecto, el vocablo empresa procede del verbo emprender. El empresario es el emprendedor. Este carácter emprendedor, elemento clave de la empresa, es característico de la clase burguesa que hizo posible el nacimiento del capitalismo. El empresario burgués es ese tipo humano tan característico de aquella época, marcado por su espíritu conquistador y aventurero en el campo económico, por su capacidad de poner en juego unos recursos económicos para conseguir una ganancia cuanto más abundante mejor, sin excluir el riesgo de terminar en el fracaso. Ganancia y riesgo son las dos caras inseparables de esa realidad que es la empresa.

Para acometer una empresa el empresario necesita disponer de unos recursos. Éstos podrán ser de su propiedad, pero podrán también proceder del patrimonio de otras personas. Cuanto mayores son las dimensiones de la empresa, más probable es que el empresario tenga que recurrir a recursos 
de otros. Es más, con el desarrollo de la economía y la creciente complejidad de la organización empresarial, la figura del empresario individual tiende a esfumarse bajo el peso de esa complicada estructura que es la empresa actual, donde se busca reducir al máximo la incertidumbre gracias a una organización altamente tecnificada que cuenta con sofisticados sistemas de gestión. Pero esta imagen de la gran empresa no debe ocultar la realidad de otras empresas, mucho más numerosas, de dimensiones más o menos reducidas. La dimensión de la empresa es un factor de diferenciación siempre a tener en cuenta para no hacer afirmaciones generales simplificadoras.

No obstante, dentro de esta diversidad de empresas hay algunos rasgos en que todas coinciden. Vamos a centrarnos en los siguientes: la empresa es unidad de producción y distribución; en ella tiene una función el progreso técnico y organizativo; ella es, finalmente, una organización. Recorreremos brevemente cada uno de ellos, poniendo de relieve las cuestiones éticas que suscitan.

\section{La empresa como unidad de producción}

Ante todo, la empresa es unidad de producción. Con este término nos referimos no sólo a la fabricación material de bienes, sino a toda actividad encaminada a poner éstos al servicio del consumidor final, en el curso de la cual se genera una utilidad mayor y, por ende, un aumento del valor económico. Objetivamente hablando, la empresa encuentra su razón de ser en el servicio que presta a la sociedad poniendo a disposición de todos los bienes y servicios adecuados para satisfacer las necesidades humanas. Así se justifica también el beneficio que obtiene, que corresponde a la retribución por el servicio que presta y que es una participación en el valor añadido que genera.

Ahora bien, esta justificación ética de las actividades de la empresa y de sus ganancias plantea algunos interrogantes sobre los que queremos reflexionar.

\section{¿De quién se satisfacen las necesidades?}

La primera de ellas pone sobre el tapete una limitación esencial a la empresa en su función de satisfacer las necesidades de la sociedad. De acuerdo con 
su propia naturaleza, la empresa no está en condiciones de responder adecuadamente a la demanda de todos los ciudadanos. En efecto, si las personas no pueden compensar a las empresas pagando el coste de producción de los bienes y servicios que les demandan, dichas personas se quedarán sin satisfacer sus necesidades. En otras palabras, las empresas son aptas para satisfacer las necesidades de sujetos solventes, pero no las necesidades de los sujetos que carecen de recursos económicos.

Esta limitación es tan esencial que cualquier intento de organización social que pretendiese apoyarse de forma exclusiva en la empresa para cubrir las necesidades de los individuos (como ocurre con los anarcocapitalistas) quedaría, a nuestro parecer, seriamente cuestionada. La empresa es un instrumento al servicio de la sociedad. Esta relación no se puede invertir poniendo la sociedad al servicio de la empresa y de su lógica del beneficio. En otras palabras, no se puede mercantilizar la sociedad ni reducirla a un gran mercado, como pretendería, explícita o implícitamente, el pensamiento único. Pero si queremos que la empresa esté al servicio de las personas y de la sociedad, y no a la inversa, hay que ser muy conscientes de las limitaciones inherentes a dicha institución y arbitrar medios que suplan sus deficiencias.

Es más, ni siquiera en el caso de sujetos solventes la empresa está en condiciones de ofrecer los medios para satisfacer todas sus necesidades. Así, si la producción de un determinado servicio requerido por la sociedad no se espera que genere beneficio en un periodo razonable de tiempo, es probable que la empresa no se ocupe de ello. Es el caso de aquellos medicamentos cuyo diseño y elaboración estima un laboratorio que va a requerir varias décadas de investigaciones sin un beneficio inmediato; 0 el de una enfermedad, cuya cura exige escasos esfuerzos investigadores, pero que afecta a escaso número de personas. Son dos ejemplos que muestran cómo la solvencia económica de un individuo no garantiza que exista una empresa que satisfaga sus necesidades, aunque sean de primer orden.

Por otra parte, existen ciertos servicios que no es recomendable se presten con estrictos criterios de gestión empresarial: la impartición de justicia, la representación política y ciudadana, la defensa del territorio, etc. De nuevo se pone aquí de manifiesto que no es posible convertir la empresa y el mercado en absolutos a los que encomendar la satisfacción de todas las necesidades de la sociedad. Ello nos obligaría a renunciar a que ciertas necesidades humanas fueran cubiertas o a pedir a la empresa lo que ésta no está en condiciones de dar ( o lo haría con una lógica que invalidaría su aportación). 


\section{¿Qué necesidades se satisfacen?}

Una segunda consideración se refiere a lo que la empresa produce o a los criterios con que selecciona lo que va a producir. Pero aquí no estamos ya ante una limitación intrínseca a la empresa, sino sobre una cuestión en que está en juego su responsabilidad ética. Ahora ya no se trata de que la sociedad supla lo que la empresa no puede hacer, sino, en todo caso, que le exija una actuación responsable. Porque en un mundo de seres humanos, la ética personal o institucional es imprescindible pero no suficiente para garantizar un funcionamiento correcto de las personas y de las instituciones.

Si la función esencial de la empresa es producir bienes o servicios que satisfacen necesidades humanas, la empresa no estará cumpliendo con esa misión si sus productos responden a necesidades generadas artificialmente o dañan positivamente a las personas. Indudablemente es difícil establecer las fronteras entre lo imprescindible, lo conveniente, lo superfluo, lo innecesario, y lo dañino. Pero, al menos, es posible llegar a ciertos consensos sobre lo que ciertos bienes o servicios de las empresas significan para el hombre. Así, por ejemplo, la producción y comercialización de ciertas drogas se sabe que dañan a la salud humana; incluso hoy se cuestionan cada vez más productos que antes se aceptaban sin reservas (caso del tabaco y el alcohol). Con seguridad existen otros productos perjudiciales, que no se cuestionan públicamente, pero de los que sus propios productores conocen 0 al menos intuyen el mal que ocasionan. En todos estos casos existe una verdadera responsabilidad ética puesto que las empresas estarían actuando abiertamente contra con la función esencial para la que existen y que legitima sus ganancias.

Mucho más difícil será llegar a consensos generalizados sobre lo que es superfluo o innecesario. Pero ciertos criterios mínimos pueden formularse. Cada empresario debe al menos saber hasta qué punto con su trabajo está satisfaciendo necesidades reales de sus semejantes o tan sólo utilizando a los demás para recibir una remuneración a cambio de algo inútil pero que se presenta como muy provechoso. En este caso se está instrumentalizando al otro, ya sea generándole necesidades artificiales, ya engañándole sobre los beneficios de lo que compra. Y hay que preguntarse entonces si la ganancia que de ahí deriva será éticamente legítima cuando está ligada a la producción de bienes que, o no son de provecho alguno o son positivamente perjudiciales. La ganancia se basa en el engaño, cuando no en un perjuicio abierto para 
las personas. A ello se une la irresponsabilidad social de estar haciendo, en cuanto agente económico y gestor de empresa, un mal uso de recursos escasos (financieros, de infraestructuras, de entorno ambiental, intelectuales), que podrían ser utilizados para otras producciones alternativas más útiles para la humanidad.

\section{La cuantía de las ganancias}

Una última consideración se refiere al beneficio empresarial en relación con el valor económico que la empresa genera. Parece incuestionable que el nivel de beneficio debe ser proporcionado al valor económico producido. No es más que una nueva aplicación del principio de proporcionalidad que invocamos en otros muchos órdenes de la vida.

En este punto la distinción entre valor y precio cobra toda su relevancia. Es verdad que en una economía de mercado el valor de las cosas suele medirse por su precio, pero ¿no es ésa una de las debilidades de nuestro sistema económico? Ante un exceso de demanda sobre la oferta, es difícil pedir a una empresa que cobre por su producto en función del verdadero valor económico del mismo y no caiga en la tentación de querer obtener unas ganancias fáciles. Pero desde un punto de vista ético no parece muy justificado el aprovecharse de la coyuntura haciendo pagar al ciudadano un precio superior al coste de producir el bien (que incluye el beneficio obtenido en una coyuntura normal y no excepcional). ¿Pueden justificarse esas ganancias que no responden al verdadero valor económico generado, sino a circunstancias externas a la propia actividad productiva de la empresa (una demanda masiva de producto)?

Es cierto que esto pretende resolverlo el mercado con el juego de la oferta y la demanda como dos variables que tienden a ajustarse automáticamente. Por eso unas ganancias extra podrían aceptarse, en ciertas condiciones, siempre que se trate de un ajuste transitorio. Pero el mercado no siempre responde con la rapidez deseada; es más, a veces se impide artificialmente que responda. Si se dice del mercado, y en parte se justifica así su existencia, que tiene la virtualidad de hacer que el precio se ajuste al valor económico, es preciso vigilar su funcionamiento e intervenir cuando las cosas no se desarrollan según este supuesto.

Esta falta de proporción entre valor y precio es algo que intuimos cuando 
nos escandalizamos ante las ganancias espectaculares de ciertas compañías o directivos de las mismas. ¿No ocurre eso muchas veces en ciertas operaciones de Bolsa? ¿No es eso lo que late, en último extremo, en la distinción que hacemos entre economía real y economía financiera?

Si esta distinción entre valor y precio es tan importante, ¿no habría que aspirar a que ciertas disciplinas económicas, como la contabilidad, no se conformasen con medir en el balance de una empresa el precio de aquélla, sino que procurasen cuantificar su verdadero valor económico? ¿Es que el verdadero valor, incluso en términos económicos, de una universidad o de un hospital es el que se desprende de su balance contable? ¿Es que en términos económicos Tabacalera vale más que la Universidad de Harvard porque así se desprende de su contabilidad? Es evidente que existen muchos intangibles que la ciencia contable no tiene en cuenta a la hora de valorar estas empresas. No se valora lo que Harvard y Tabacalera aportan a la sociedad, ni por ejemplo se tiene en cuenta el principal "activo" de una empresa: su personal. ¿Podría pensarse que una ciencia contable que se preocupase por esas cuestiones corrigiese el rigor de las leyes del mercado y destacase otros aspectos de la realidad?

\section{La empresa como unidad de distribución}

La empresa, además de unidad de producción, es también el primer instrumento de distribución de la renta producida, haciéndola llegar a los factores de producción, esencialmente trabajo y capital. Esta es otra de las grandes aportaciones de la empresa a la sociedad, que tiene evidentemente una importante dimensión ética. Y por eso es conveniente también hacer algunas consideraciones que clarifican las condiciones para que esta función se realice de forma éticamente aceptable.

\section{¿Cómo se determina la distribución dentro de la empresa?}

La empresa distribuye la renta que ella genera, y lo hace entre los agentes que contribuyen a generarla. Todos tienen derecho a participar del valor económico que han ayudado a crear: accionistas, directivos y trabajadores.

Pero es más fácil enunciar el principio general que cuantificar la aportación de cada grupo y fijar, consecuentemente, la proporción que les corresponde. 
Son tan heterogéneas entre sí las aportaciones de cada grupo que no cabe un criterio único para determinar las cuotas de todos. Sí es posible excluir al menos un mecanismo para la distribución: que ésta se haga en función del poder de cada grupo. Que estos poderes existen es cosa imposible de negar. Si no parece prudente confiar sin más en ellos, habrá que arbitrar mecanismos compensatorios para evitar que se imponga siempre la ley del más fuerte.

Todavía se puede matizar algo más la justificación que de las ganancias del capital se ha dado en el pasado y se sigue haciendo con frecuencia hoy. Se solía decir que la ganancia del capital (muchas veces identificado sin más con el empresario) estaba justificada, no sólo por su contribución al proceso productivo (sin duda, de inestimable valor), sino además por el riesgo económico que asumía ante la posibilidad de obtener pérdidas. Dejando de lado lo que ocurriera en el pasado, es innegable que hoy dicho riesgo tiende a reducirse al máximo gracias, en primer término, a un ordenamiento jurídico que ha ido evolucionando en el sentido de limitar las responsabilidades de los propietarios del capital ( ¿qué significa, si no, la creación de sociedades en que el riesgo sólo afecta al patrimonio aportado a la misma?); y se reduce también gracias a las nuevas técnicas de gestión, cada vez más sofisticadas.

Más aún, si pensamos en el contexto actual y en el alto nivel de desempleo que le caracteriza, es difícil admitir que el accionista corra un riesgo superior al que corre el trabajador: éste perderá, no sólo su principal medio de subsistencia (lo que difícilmente ocurrirá en el caso del accionista), sino probablemente además su principal elemento de integración en la sociedad y de realización personal, cosas ambas tan ligadas al desarrollo de una actividad laboral.

\section{¿Es la empresa la única vía de distribución de la renta?}

Admitido que la empresa es un importante mecanismo de distribución de la renta de la sociedad -entre otras razones, porque dicha renta se genera precisamente en la actividad productiva de las empresas-, hay que añadir en seguida que ella no es la única vía por la que se realiza esa importante tarea en la sociedad.

Las limitaciones de la empresa para realizar adecuadamente esta función obliga -ya lo indicamos- a buscar vías complementarias. Normalmente se 
habla de "redistribución", lo que implica dos cosas: que la distribución primaria es la que realiza la empresa; y que no siempre es satisfactoria. De nuevo nos encontramos con que la lógica de la empresa, que es la lógica del intercambio equivalente, no es suficiente para resolver todos los problemas económicos de la sociedad, ni siquiera para distribuir adecuadamente los recursos producidos entre todos los ciudadanos y facilitarles así medios para satisfacer sus necesidades.

Hoy, sin embargo, no son pocos los que propugnan reducir al mínimo cualquier intervención que corrija ulteriormente lo que la empresa realiza según la estricta lógica del mercado. Nosotros nos vemos de nuevo en la obligación de repetir que la sociedad no puede organizarse desde los presupuestos exclusivos del mercado. La cuestión de la distribución de la renta es un nuevo caso de lo que estamos diciendo.

\section{Progreso permanente en la empresa}

En todo lo que la empresa hace conserva aquel rasgo emprendedor originario: mantiene el sentido de innovación y renovación constantes, de progreso. No se contenta con producir; busca la forma de producir en las condiciones más ventajosas para ella, ganando así una batalla siempre abierta con otras empresas que producen los mismos o semejantes bienes.

Este afán de progreso y mejora tiene al menos un doble efecto enormemente beneficioso para la sociedad: por una parte, dará lugar a mejoras tecnológicas que permitirán una mejor satisfacción de las necesidades; por otra, servirá en muchas ocasiones para reducir los costes de producción, lo que hará los bienes más accesibles a todos. Pero esa renovación constante tiene sus aspectos éticos, que no se pueden ignorar.

\section{¿Empeorar la calidad para reducir costes?}

No es suficiente que el objetivo de la innovación sea sólo la reducción de los costes, sobre todo si esta reducción no repercute sobre el consumidor final. Sería preferible buscar siempre un justo equilibrio entre precio y calidad.

La experiencia reciente muestra más bien que los esfuerzos tienden a orientarse a conseguir un precio competitivo, y no tanto un producto competitivo (lo que incluiría, no sólo la variable precio, sino calidad). Un ejemplo 
muy actual lo tenemos en un sector tan dinámico como el de las telecomunicaciones y la informática: ¿no se ha privado definitivamente a la sociedad de productos, sistemas y tecnologías de más calidad, porque la variable precio ha impuesto su ley férrea sobre la variable calidad? Tampoco parece muy razonable que, en lugar de investigar para mejorar la calidad del producto, se dediquen cantidades ingentes de dinero a estudiar cómo mejorar el envase o la presentación del producto, o cómo dar a conocer el mismo a la sociedad mediante agresivas técnicas de marketing. ¿No ocurre entonces que lo adjetivo acaba ocupando el lugar de lo sustantivo?

Es evidente que a las empresas no se les puede pedir milagros, ni que renuncien a la competitividad que les exige las condiciones actuales de la economía globalizada. Pero sí puede plantearse en qué se pone la competitividad: si sólo en el precio, o en la relación calidad-precio, lo que exige una tarea complementaria de información al consumidor.

Pero ésta es una tarea que desborda completamente el ámbito en que se mueve la empresa y exige un adecuado protagonismo de la sociedad y, más en concreto, de los consumidores. No basta exigirle a la empresa un comportamiento ético: ya hemos indicado que son precisos mecanismos institucionales que impidan los abusos ( 20 es que medicamentos, servicios médicos, enseñanza reglada, etc., no son controlados por otras instituciones ajenas al mercado?); ahora añadimos que, entre esas instancias, hay que contar con un consumidor maduro e inteligente.

\section{Reducir costes, pero ¿por qué vías?}

Pero a la ética no sólo le corresponde llamar la atención sobre el para qué de esa constante innovación y mejora; también debe estar atenta a cómo se llega a esos logros tecnológicos o de gestión. ¿A costa de qué y de quién se alcanzan esas metas? Veamos dos ejemplos ilustrativos que, por desgracia, no son meros supuestos teóricos.

¿Es aceptable conseguir coches excelentes, pero sometiendo a los empleados al yugo psicológico que supone una cadena de montaje o un desquiciante régimen de trabajo por turnos? Las mejoras tecnológicas en la producción no pueden hacerse a costa del ser humano. Supeditar la salud física o psíquica del trabajador a la optimización de la producción es reducir la persona a mero instrumento al servicio de otros fines. Habría que recordar el imperativo 
ético formulado por Kant: considerar a nuestros semejantes como fines y no como medios.

Un segundo caso: ¿es admisible obtener un producto barato y de calidad, a costa de una fuerte contaminación ambiental? ¿Puede apoderarse la empresa de recursos o bienes que no le pertenecen, consumiéndolos (más bien destruyéndolos) en el proceso de producción? El agua, el mar, los bosques, los ríos, pertenecen a la sociedad, no a las empresas. Son propiedad de todos. Que todos puedan disfrutarlos implica que nadie se crea en el derecho de consumirlos (o destruirlos) en provecho propio.

En este sentido ni siquiera basta con el principio de "quien contamina paga". No cabe duda que su aplicación, si no se entiende sólo como una multa, es una forma de pagar el coste de lo consumido o de descontaminar lo contaminado. Pero esta compensación presente no repara el daño infringido a quienes, hoy o en el futuro, tienen derecho a seguir disponiendo de ellos. Por tanto, lo primero es "no contaminar" (en el sentido de consumir innecesaria o fraudulentamente); y en el caso de que haya que consumir recursos naturales (lo que es, tantas veces, inevitable), pagar en función de lo consumido para no convertir los costes sociales en beneficios privados.

\section{La empresa como organización}

Las actividades empresariales son posibles gracias a la existencia de un grupo humano, que constituye una organización. Una organización es un conjunto de personas, que se ponen de acuerdo para perseguir unos fines mediante una acción coordinada en que cada uno asume una tarea. Lo propio de la empresa como organización es su finalidad lucrativa; pero esta circunstancia específica, que hemos considerado en todo lo que precede, no es óbice para acercarnos a la empresa como una organización y analizar los aspectos éticos que dimanan de esta perspectiva.

El carácter de organización nos permite comprender mejor la finalidad y razón de ser de la empresa. La coordinación de esfuerzos y el reparto de tareas en ella tienen un fin: producir unos bienes o servicios aptos para satisfacer la demanda social. Este es el fin objetivo de toda empresa, su razón de ser social. Este fin será valorado positivamente por la sociedad siempre que lo que empresa produce sea bueno para las personas y para la sociedad misma. Ahora bien, los que se unen en la organización productiva no buscan 
sólo satisfacer necesidades humanas ( ¡ojalá ese sentido último de la actividad productiva siempre estuviese presente!). Para ellos esa actividad productiva tiene un papel instrumental, es un medio para obtener otra cosa: un beneficio económico. A esto podemos llamarlo finalidad subjetiva de la empresa, porque expresa las motivaciones que llevan a los miembros de la organización a implicarse en la actividad productiva.

Más aún, esta finalidad subjetiva de la empresa, en principio común a trabajadores, directivos y propietarios del capital, tiende a diversificarse después según los intereses particulares, y muchas veces contrapuestos, de esos tres colectivos. Estamos entonces en el problema de la distribución, que ya analizamos más arriba.

\section{El trabajo como actividad humana y humanizadora}

La consideración de la empresa como organización permite destacar mejor su dimensión humana, y concretamente la actividad humana de sus miembros. Dicha actividad, el trabajo, no sólo reporta a quienes lo realizan unos recursos económicos merecidamente obtenidos, sino que contribuye a su realización como personas y a su integración en la sociedad. Sólo cuando se carece de empleo y no se forma parte de una empresa se percibe hasta qué punto se trabaja, no sólo para obtener unos recursos económicos, sino para no sentirse improductivo y marginado. ¿Hasta qué punto debe asumir la empresa estos anhelos de las personas que desarrollan en ella su actividad?

Cualquier respuesta a esta pregunta debe comenzar atendiendo a la diversidad de actividades que engloba el trabajo. Por ejemplo, una empresa que produce carbón, por bien que cumpla con su finalidad objetiva de producir bienes útiles para la sociedad y por escrupulosa que sea con las normas de seguridad e higiene en el trabajo, difícilmente conseguirá que sus trabajadores (los mineros) se desarrollen a través de su trabajo como lo hace una persona que escribe una novela o diseña un edificio. Porque la psicología muestra cómo lo que humaniza a la persona es una actividad en la que pueda desplegar ciertas dosis de creatividad. Pero esto es difícil cuando la producción exige del trabajador una actividad totalmente repetitiva y además cargada de peligro...

¿Hay que resignarse entonces a que la realización humana a través de una actividad que sea digna de la persona se remita al tiempo extralaboral? 
¿Debe la sociedad organizarse en este sentido, y desentenderse de lo que el trabajo productivo (muchos trabajos) tienen de inhumano o deshumanizante?

Pensamos que hay que armonizar ambas líneas de actuación porque no basta con soñar con la sociedad del ocio, aunque eso esté ya en un horizonte no tan lejano y haya que prepararse para cuando llegue. Pero nada de esto puede excluir el esfuerzo por limitar el carácter deshumanizante del trabajo hoy. Más aún, y dicho ahora en sentido positivo: el objetivo de humanizar el trabajo debe ser asumido responsablemente por toda empresa, aun sabiendo que entrará muchas veces en conflicto con otros objetivos (la rentabilidad...).

\section{El trabajo como forma de integración social}

Por otra parte, por muy poco humanizador que sea el trabajo de muchos, el hecho de tener trabajo es ya un factor de integración social de enorme valor psicológico y social. Porque son tres las cosas que más desestructuran a una persona: la falta de familia (al menos en las etapas iniciales de la vida), el ser un apátrida o el no formar parte de una entidad productiva (ya sea empresa, Administración, etc.). Y es que familia, Estado y empresa son las tres principales "instituciones" (ya naturales o sociales) que articulan las sociedades: es fundamentalmente a través de dichas instituciones como el individuo se integra en una sociedad y se identifica como sujeto y parte de la misma.

Ante esta importancia del trabajo para la integración social hay que preguntarse nuevamente por la responsabilidad ética. Es evidente que no toda la responsabilidad de la creación y mantenimiento del empleo puede encomendarse a la empresa, a cada empresa concreta. Pero este aspecto no puede estar del todo ausente cuando en la empresa se toman decisiones que afectan al trabajo. Si toda persona, y por ello también el empresario o directivo, debe valorar las consecuencias que su decisión tiene para él y para los demás, ¿cómo ignorar lo que significa un puesto de trabajo cuando hay que decidir sobre despidos, movilidad funcional, etc.?

Es más, si la sociedad otorga a las empresas un trato privilegiado ( reconocimiento del principio de libertad de empresa, infraestructuras diversas que benefician esencialmente a las actividades empresariales, bolsas de 
valores, tribunales de defensa de la competencia, beneficios fiscales para las actividades económicas, etc.), ¿no será porque implícitamente se pide a las empresas algo más que la mera producción de bienes o servicios? ¿es injusto o desproporcionado que se les exija un esfuerzo para crear y mantener el empleo? Si la deuda de la sociedad con las empresas es grande, no es menor la de éstas con la sociedad...

En todo caso el problema del desempleo es hoy tan grave (debido a las funciones insustituibles que tiene el trabajo en nuestra sociedad) que no podemos quedarnos tranquilos garantizando y aun ampliando unos subsidios de tipo económico a los desempleados. ¿No hay que avanzar buscando por otros derroteros la realización de las personas y su integración en la sociedad? Pero este tema, que desborda lo estrictamente económico y se adentra ya en el ámbito de la cultura, trasciende por completo de los límites de estas reflexiones...

\section{Conclusión}

Al llegar al final de estas páginas recordamos cuál era nuestra intención inicial: sencillamente, sembrar inquietudes éticas en torno a la empresa, dado que ella es una institución decisiva en las sociedades modernas. A lo largo de nuestras reflexiones hemos repetido en más de una ocasión que ciertas tareas desbordaban las posibilidades de la empresa. Pero esto no debe interpretarse como deseo de excusar a la empresa y liberarla de toda responsabilidad social. Sólo queríamos plantear una serie de preocupaciones éticas que surgen al considerar los distintos aspectos de la vida de la empresa: unos remiten a la propia responsabilidad de ésta, mientras que otros cuestionan a la sociedad toda y a otros colectivos sociales.

Hoy se habla mucho de reconstrucción ética de la sociedad. Pero esto no será posible sin la implicación efectiva de individuos, grupos sociales, instituciones, sociedad toda. Sólo así irá renaciendo una cultura impregnada por valores éticos, donde el respeto debido al pluralismo de mentalidades se armonice con un consenso básico que permita una convivencia pacífica. Para eso hay que huir de posturas más propensas a "restar" que a "sumar": es decir, no es buen camino descargar siempre sobre "los otros" (sea la empresa o el capital, sean los políticos) la culpa de los males de nuestra sociedad; sólo cabe distribuir responsabilidades de forma que todos asuman la suya como complementaria de la de los demás. 
Por lo que respecta a la empresa, que era el tema directo de nuestras reflexiones, es cierto que no todo depende de ella, pero no es menos verdad que su responsabilidad directa e indirecta para la humanización de la sociedad es decisiva. Y eso implica, desde luego, definir lo que corresponde a la empresa, reconocer lo que no puede asumir porque desborda sus funciones, y en todo caso no empeñarse en mercantilizar la sociedad haciendo que la lógica del mercado sea la única ley que gobierne la convivencia humana. 